\title{
MULA DE DEUS: O IMPOSSÍVEL PEDIDO
}

\author{
Rubens da Cunha \\ Mestrando do Curso de Pós-Graduação em Literatura - UFSC
}

\begin{abstract}
RESUMO
O presente ensaio aborda o poema "Mula de Deus", publicado no último livro de Hilda Hilst, a narrativa Estar Sendo. Ter Sido. Trata-se de um poema de despedida, de finalização, tanto do livro, quanto do projeto literário de Hilda Hilst. A princípio, o ensaio estabelece uma separação entre a persona personalis e persona ficta de Hilda Hilst. Para isso, utiliza-se a idéia de Agamben, à luz de Foucault, do "autor como gesto", do autor como uma testemunha de sua própria ausência. Depois, uma breve análise da estrutura do poema, tendo por fundamento o texto "O fim do Poema", também de Giorgio Agamben. Por fim, é desenvolvida uma leitura das súplicas, suplícios, fracassos, bem como da dualidade da vergonha que atravessa o poeta-mula, um ser desejante da possessão divina.
\end{abstract}

\section{PALAVRAS-CHAVE}

Hilda Hilst; Vergonha; Possessão; Experiência Interior.

\section{MULA DE DEUS: THE IMPOSSIBLE REQUEST}

Today's essay approaches the poem "Mula de Deus", published in the latest narrative Estar Sendo. Ter Sido by Hilda Hilst. Both, poem and narrative, are a kind of farewell and finalization to the Hilda Hilst literary project. Firstly, it is established a distinction between the Hilda Hilst persona personalis and her persona ficta. To make this, it is utilized the Agamben's idea, lighting Foucault, of "the author as gesture" and the author as witness of his own absence. After, a short analysis of structure's poem based on the text "The End of the Poem" by Giorgio Agamben as well. Finally, it is developed a reading about the poet-mule, its prayers, tortures, failures and also the duality of shame inside this desiring creature of divine possession.

\section{KEYWORDS}

Hilda Hilst; Sense of Shame; Inner Experience. 
Equus Mulus. A mula, o animal híbrido. A filha do jumento com a égua. Da mãe herda a força e o tamanho; do pai lhe resta a servilidade e a resistência. Nada transmitirá, estéril, incapaz de transcender, descender, eternizar-se. A mula, imanente em seu corpo pardacim e fosco. A mula escrava, carregadora de fardos, equilibrista, a mula sempre recebedora dos achaques, dos açoites humanos. Que outro animal melhor serviria de metáfora para o poema final da obra de Hilda Hilst? Que outro animal daria conta de ser a montaria de Deus, a possuída de um Deus cheio de escracho e indiferente? Nem o cavalo com sua elegância, nem o asno com seu tamanho breve, nem o camelo com sua falta de sede, nem o elefante com seu gigantismo, é preciso que seja a mula, a bastarda, a degenerada da espécie, só ela, a vergonhosa mula, conseguirá carregar uma locução adjetiva tão extrema: de Deus.

\section{A SEPARAÇÃO DOLOROSA: "PERSONA PERSONALIS VS. PERSONA FICTA"}

"Mula de Deus" é um poema isolado nas últimas páginas de Estar Sendo. Ter Sido. livro testamento, livro carregado com as decrepitudes da velhice, com a loucura gritadora de um personagem que só espera a morte. Inevitável a aproximação com a autora. Inevitável ser chamado pelo canto de sereia de Hilda Hilst, mavioso canto que nos afasta da obra e nos faz mergulhar no mar biográfico, no mar-máscara que Hilda construiu para si. Alcir Pécora, organizador das obras completas para a Editora Globo, no texto "Hilda Hilst: call for papers" ${ }^{1 "}$ discorre sobre a "persona personalis vs. persona ficta" afirmando:

Embora a autora tenha alcançado grande notoriedade pessoal, por conta de uma inteligência incomum, de um temperamento verdadeiramente exuberante, e de uma prontidão de espírito capaz de sempre surpreender as

\footnotetext{
1 PECÓRA, Hilda Hilst: call for papers. In: http://www.germinaliteratura.com.br/literatura ago2005 pecora.htm. Escrito em agosto de 2005. Acesso em 24 de Julho de 2009. Na introdução do texto, pécora afirma que a Unicamp estava interessada em realizar um congresso internacional sobre a obra de Hilda Hilst, que seria realizado no ano de 2006. Então ele apresentou um "mapeamento preliminar das questões pertinentes ao conjunto da obra de Hilda, que possa ser eventualmente interessantes para balizar o amplo call for papers do futuro congresso". Em pesquisa no site da Unicamp, não foram encontradas informações sobre este congresso, o que indica que ele ainda não tenha sido realizado.
} 
pautas banais das entrevistas, parece-me relevante enunciar aqui que a sua obra, de rara extensão e variedade, ainda é largamente desconhecida. A rigor, a meu ver, ela jamais obteve uma única crítica suficientemente abrangente e esclarecedora, a despeito de ter havido uma ou outra leitura bem feita de textos particulares. O mais foi atribuir-lhe aquele mesmo tipo de encômio clichê que se confirmou amplamente no noticiário de sua morte: mulher ousada, original, avançada para a sua época, louca refinada e explosiva etc. [...] A celebridade Hilda Hilst não passa de ficção barata, como todas as do gênero, e nada diz da pessoa Hilda Hilst, além de descaradamente mentir ou desconversar sobre as questões mais incômodas de sua obra invulgar. [...] O principal esforço da crítica interessada no trabalho de Hilda Hilst, hoje, é justamente esquecer, ainda que em termos estratégicos, a extraordinária pessoa (e amiga adorável, se me é permitido uma nota pessoal) que ela foi, durante toda a vida. A extraordinária pessoa que foi ainda mais ao longo de seu difícil final - que é quando mais se afere o valor de um caráter, segundo a velha tópica do último combate, no qual, dependendo de como se perde, e necessariamente se perde, então se vence.

Pécora também aponta outras questões como determinantes do predomínio da imagem pública de Hilda como tipo excêntrico sobre o conhecimento real de sua obra. São questões que envolvem o comportamento liberal da autora; a distância que ela mantém dos valores modernistas em voga no Brasil, naquela preferência por um conteúdo mais "nacional" de literatura, que nunca lhe coube; a dificuldade de leitura de seus textos, principalmente os de prosa, que exigem uma erudição literária, filosófica e até científica; a mistura de gêneros literários em cada texto; o afastamento de Hilda do convívio intelectual desde os anos 60; a publicação sua obra sempre em pequenas edições e com pouca distribuição ${ }^{2}$.

Escapar da persona personalis de Hilda, separar-se, distanciar-se do seu encantamento e deter-se, ater-se no texto, afastar-se do perigo de "nos colarmos à ficcionalização de si mesma" ${ }^{3}$ talvez seja o trabalho mais complexo de quem pretende estudar a sua obra, mas também o mais necessário para que o olhar sobre o poema, derrideanamente, deixe a estrada.

"Mula de Deus" é um acontecimento, um derradeiro grito, ou usando novamente a imagem de Derrida, o último ouriço enrolado na estrada, talvez o mais protegido e o mais exposto ao acidente. O poema cujos espinhos se abrem como ferida e abrem a ferida ${ }^{4}$, a meu ver, mais perigosa, pois "Mula de Deus" é o poema mais próximo da morte, não apenas do projeto literário de Hilda que se encerra nele, mas da própria Hilda que depois encerrou-se em si mesma, silenciou. Silenciou-se. Foram quase

2 PECÓRA, H. Hilda Hilst: call for papers.
http://www.germinaliteratura.com.br/literatura ago2005 pecora.htm. Escrito em agosto de 2005. Acesso em: 24 jul. 2009.

3 DUARTE, Edson Costa. Hilda Hilst - A Poética da Agonia e do gozo. In: http://www.revista.agulha.nom.br/hilda.html. Acesso em: 24 jul. 2009.

${ }^{4}$ DERRIDA, J. Che cos'é la poesia? In: Inimigo Rumor. n. 10. Rio de Janeiro: 7 Letras, maio 2001. 
cinquenta anos produzindo prosa, poesia e teatro que abordam temas profundos e profanos, tais como o erotismo, a morte, a loucura, tabus sexuais, escatologias ${ }^{5}$, um fluxo contínuo de poemas e narrativas supondo "uma reflexão dura sobre o sentido de escrever, que se desdobra na ideia do Deus Criador, cuja forma se revela apequenada e vil", persona da grande escritora, da incompreendida, da vítima de uma maldição que ela batizou de "potlatch", apropriando-se do termo lido em Bataille, pois considerava sua obra desperdiçada pela sociedade brasileira. Para ler o poema "Mula de Deus" sem ser seduzido pela voz pessoalíssima de Hilda Hilst, uma possibilidade é assumir, como leitor, o jogo proposto por Agamben quando fala, à luz de Foucault, do "autor como gesto":

O lugar - ou melhor, o ter lugar - do poema não está, pois, nem no texto nem no autor (ou no leitor): está no gesto no qual autor e leitor se põem em jogo no texto, e ao mesmo tempo infinitamente fogem disso ${ }^{7}$.

Assumir que o autor "nada pode fazer além de continuar, na obra, não realizado e não dito ${ }^{8}$ " mas que é essa ilegibilidade que torna possível a leitura e "esse gesto do autor é atestado na obra a que também dá vida, como uma presença incongruente e estranha",, ou seja, uma ausência que instaura o jogo, ou conforme Raúl Antelo: "o autor é tão-somente a testemunha, o fiador de sua própria ausência na obra, cabendo ao leitor, por sua vez, retraçar essa ausência como infinito recomeço do jogo 10 ,"

Tal Ulisses, amarrado ao mastro, ouvindo a voz sedutora, prenhe de vontade de ceder ao canto, mas sabendo que o "sujeito não é algo que possa ser alcançado como

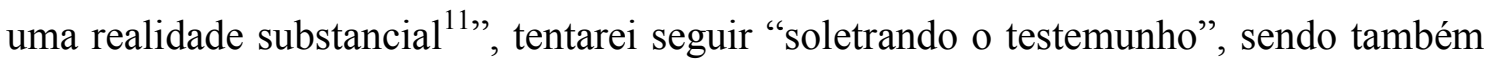
um gesto em torno do poema "Mula de Deus".

\section{MULA DE DEUS: ALGUMA ESTRUTURA}

\footnotetext{
${ }^{5}$ O crítico Leo Gilson Ribeiro no prefácio de Ficções, publicado em 1977 pela Quíron, estabelece que Hilda Hilst reúne duas escatologias: "A do Eskhatoslogos, a doutrina final dos tempos e a do Skatoslogos, a doutrina que disserta sobre as fezes.” p. 11. In: HILST, Hilda. Fiç̧ões. São Paulo: Quíron, 1977

${ }^{6}$ PÉCORA, A. Nota do organizador. In: Estar Sendo. Ter Sido. p. 8

${ }^{7}$ AGAMBEN, G. Profanações. São Paulo: Boitempo, 2007 p. 62-63.

${ }^{8}$ Idem, p. 61

${ }^{9}$ Idem, p. 61

${ }^{10}$ ANTELO, Raúl. O autor como gesto. À memória de Ronaldo Assunção: In Alea: Estudos Neolatinos. Print version ISSN 1517-106X. Alea vol.7 n.2 Rio de Janeiro Jul/Dec. 2005. Acesso em: 26 jul 2009: http://www.scielo.br/scielo.php?pid=S1517-106X2005000200011\&script $=$ sci arttext
}

${ }^{11}$ AGAMBEN, G. Profanações. São Paulo: Boitempo, 2007 p. 63 
"Mula de Deus" não destoa das características formais presentes em toda a obra poética de Hilda Hilst. Um longo poema, dividido em oito partes, presos a uma espinha dorsal temática anunciada pelo título. Desde Presságio, o primeiro livro da autora, lançado em 1950, pela Revista dos Tribunais, tal forma se manteve como a tônica de seus livros de poemas. São raros os poemas que não se subdividem. Essa estrutura até permite a leitura das partes como poemas isolados, mas fica-se sempre com a sensação de que a totalidade da expressão, ou o que Agamben, a partir de Valéry, define como sendo poesia: a "tensão e o contraste (e também na possível interferência) entre o som e o sentido, entre a série semiótica e a série semântica ${ }^{12}$ " foi de alguma forma amputada, cerceada pela leitura de apenas algumas partes.

Por outro lado, esse tipo de estrutura causa uma quantidade maior do "desarranjo do último verso", denominado por Agamben como "o fim do poema”. Para Agamben é

como se o poema, enquanto estrutura formal, não pudesse, não devesse findar, como se a possibilidade do fim lhe fosse radicalmente subtraída, já que implicaria esse impossível poético que é a coincidência exata de som e sentido. No ponto em que o som está prestes a arruinar-se no abismo do sentido, o poema procura uma saída suspendendo, por assim dizer, o próprio fim, numa declaração de estado de emergência poético ${ }^{13}$.

Assim, no caso de "Mula de Deus", trata-se de um poema que tem oito "saídas" para suspender o próprio fim, pois no final de cada uma das parte-poemas constitutivas do grande poema, a sonoridade advinda de seu último verso para, mas os sentidos continuam em direção a um espaço totalmente aberto à ideia do poema. Em "Mula de Deus" esses sentidos se encontram e se juntam no salto com os versos finais do poema, que exerce dupla função: ser o final da oitava parte, mas também ser o final de todas as outras partes e estar naquele lugar onde "o som está prestes a arruinar-se no abismo do sentido". (Aunque pueda parecer / que del poeta es locura) ${ }^{14}$ é o final de "Mula de Deus": um dístico entre parênteses, em itálico e em espanhol, além de ser um enjambement. Trata-se de um dístico estabelecendo a saída definitiva, que suspende o próprio fim do poema, "numa declaração de estado de emergência poética ${ }^{15}$."

\footnotetext{
${ }^{12}$ AGAMBEN, G. O fim do poema, In: Cacto. 2002 p. 142

${ }^{13}$ Idem, p. 146

${ }^{14}$ HILST, H. Estar Sendo. Ter Sido. São Paulo: Globo, 2006 p. 127

${ }^{15}$ AGAMBEN, G. O fim do poema, In: Cacto. 2002 p. 146
} 


\section{DA VERGONHA E DO SILÊNCIO FINAL}

Mesmo que possa parecer loucura, há em "Mula de Deus" muito mais do que a locura del poeta. Poema que, apesar de se inscrever na tradição hilstiana de fazer poemas, tem uma diferença fundamental: o lugar e a circunstância em que ele foi publicado, nas páginas finais do livro final, a narrativa Estar Sendo. Ter Sido., o último livro, editado originalmente pela Nankin em 1997. Estar Sendo. Ter Sido., segundo Alcir Pécora, tem como o "imperativo ético, exclusivamente, de não se furtar ao desengano da vida em face da iminência da morte ${ }^{16}$." O ponto final desse imperativo é o poema "Mula de Deus", uma animalização do poeta, do poeta-mula, ou mais especificamente em Estar Sendo. Ter Sido., do narrador-mula. Alcir Pécora, na apresentação do livro fala sobre o fluxo de consciência, recurso básico nas narrativas de Hilda, diz que o fluxo tem a forma de uma

profileração de vozes simultânea à fragmentação delas. Trata-se de uma cena de possessão - no qual o narrador, fazendo às vezes de cavalo - ou de mula, como Hilda Preferia -, é sucessivamente montado por entes poucos definidos, semelhantes entre si, incapazes de conhecer a causa ou o sentido de sua coexistência na escrita. Testemunham, entretanto, todos eles, uma dor ou carência essencial, que equivale à compreensão de que escrever é preencher folhas de papel com pânico e solidão, com a suspeita de ter perdido o rumo ou de nunca ter havido algum ${ }^{17}$.

O poema "Mula de Deus" não traz uma cena de possessão igual às muitas vistas na narrativa, mas está implícito nele a ideia de um "culto pela possessão" como pode ser visto em Mario Perniola, quando este fala sobre técnica e possessão, e afirma que o homem barroco tem o ânimo suspenso, silencioso, na escuta por algo que vem de fora, e que isso determina a sua emotividade ${ }^{18}$. "Mula de Deus" aponta a própria condição da mula, é o espaço no qual o poeta-mula se pronuncia, o lugar em que podemos entender como se prepara a suspensão do ânimo, que animalização e submissão é essa que se presentifica no poema final e por que o poeta-mula deseja tanto ser possuído, montado por um Deus esquivo e indiferente. O poema é a exposição de alguns recursos retóricos, comportamentais, até chantagistas, que o poeta-mula usa para atingir a atenção do divino e ter dele as benesses de uma possessão, e com isso ter

\footnotetext{
${ }^{16}$ PÉCORA, A. Nota do organizador. In: Estar sendo. Ter sido. p. 8

${ }^{17}$ Idem, p. 9

${ }^{18}$ PERNIOLA, M. Enigmas, Egipcio, barroco y neo-barroco em la sociedad y El arte. Murcia: CendeaC / Ad Litteram Ensayo, 2005. p. 118
} 
alguma emotividade para além do sofrimento, bem como ser beneficiado com uma morte mais amena e mais digna do que as vidas que teve até então.

"Mula de Deus" pode ser lido como um desdobramento Poemas malditos, gozosos e devotos, livro de Hilda Hilst publicado em 1984 pela Massao Ohno, composto por vinte e um poemas ${ }^{19}$, todos na forma de apóstrofe, diretamente direcionados a Deus, que neste livro se transforma numa constante não-presença, numa ameaça de vazio, mas ao mesmo tempo é um "sedutor nato" ${ }^{20}$ que vive "do grito dos seus animais feridos"21, por isso recebe versos-perguntas incisivos, ameaçadores, mas ao mesmo tempo carregados de desespero ante a certeza que pensar Deus, se direcionar a ele é um exercício de solidão e de "compor na carne um discurso de ausência, de desejo sem nenhuma correspondência ${ }^{22}$."

É como se o poeta-mula xucro de Poemas malditos, gozosos e devotos, envelhecesse e tivesse não apenas tomado consciência do exercício da solidão, mas também da possibilidade de realmente não ser mais um "possuído", um "notado" por esse Deus tão achincalhado e tão amado. Há uma atenuação na voz, há um comedimento político no posicionamento do poeta-mula que inicia sua fala-súplica numa estrofe indicadora desse posicionamento: "para fazer sorrir O MAIS FORMOSO / alta, dourada, me pensei./ Não esta pardacim, o pelo fosco / pois há de rir-se de mim, O PRECIOSO $^{23}$." Agamben afirma:

Segundo a teologia, o castigo mais severo em que pode incorrer uma criatura, aquele contra o qual não há mesmo mais nada a fazer, não é a cólera de Deus, mas o seu esquecimento. De facto, a Sua cólera tem a mesma natureza que a Sua misericórdia ${ }^{24}$.

Padecer desse esquecimento, desse abandono vai para além de todo castigo, é algo que o poeta-mula já não pode aguentar ${ }^{25}$, por isso a constante submissão, a vergonha em ter feridas, ter o pelo fosco e a necessidade de ressaltar sua condição de humilde na estrofe final dessa primeira parte do poema: "se me vires, SENHOR, perdoa

${ }^{19} \mathrm{Ou}$ parte-poemas, pois conforme já abordado anteriormente, a estrutura dos poemas se mantém a mesma, com todas as partes girando em torno do título formando um grande poema.

${ }^{20}$ HILST, H. Poemas malditos, gozosos e devotos. São Paulo: Globo, 2005. p. 17

${ }^{21}$ Idem, p. 13

${ }^{22}$ PECORA, A. Nota do Organizador. In: Poemas malditos, gozosos e devotos. São Paulo: Globo, 2005 p. 12

${ }^{23}$ HILST, H. Estar Sendo. Ter Sido. São Paulo: Globo, 2006. p 123. A escrita dos adjetivos que qualificam Deus em letras maiúsculas denota também um posicionamento de inferioridade ao sagrado. O recurso não foi usado em Poemas Malditos, gozosos e devotos.

${ }^{24}$ AGAMBEN, G. Ideia da prosa. Lisboa: Cotovia, 1999 p. 69

${ }^{25}$ Em Poemas malditos, gozosos e devotos, Deus era incitado a chorar, porque esqueceria o poeta. "Chora por mim. Pela poeira que fui / Serei, e sou agora. Pelo esquecimento / que virá de ti e dos amigos." HILST, H. Poemas malditos, gozosos e devotos. São Paulo: Globo, 2005. Parte-poema XXI, p. 63 
ainda/ é raro em sendo mula, ter a chaga / e ao mesmo tempo / aparência de limpa partitura / e perfume e frescor de terra $\operatorname{arada}^{26}$."

Estar sendo, ter sido, é a condição primordial do poeta-mula diante do "MAIS FORMOSO”. Estar sendo mula na sua decrepitude máxima, na sua velhez aterradora, estar sendo nada digno da possibilidade de uma possessão, de um olhar, ainda que distante, ainda que último, do Deus indiferente, faz com que o poeta-mula recorra ao ter sido:

\author{
Um dia fui o asno de Apuleius. \\ Depois fui Lucius, Lucas, fui Roxana. \\ Fui mãe e meretriz e na Betânia \\ toquei o intocado e vi Jeshua. \\ (Ele tocou-me o ombro aquele Jeshua pálido) \\ Um tempo fui ninguém: sussurro, hálito. \\ Alguém passou, diziam? Ninguém, ninguém. \\ Agora sou escombros de um alguém. \\ Só caminhada e estio. Carrego fardos \\ aves, patos, esses que vão morrer. \\ iguais a mim também ${ }^{27}$.
}

Em busca dessa memória anterior, dessa tentativa de atingir uma origem, alguma importância maior, o poeta-mula começa pelo "asno de Apuléius"28 e a partir disso vem se metamorfoseando no transcorrer do tempo, mas sempre se tornando ínfimo, menor do que havia sido, como se fosse um processo radical de depuração da alma, pensando dentro da teoria kardecista ${ }^{29}$. A depuração do poeta-mula vai tornando-o fisicamente insignificante. O desaparecimento substancial e doloroso de um corpo, mesmo asinino, que era cheio de orgulho, torna-se outro recurso para conseguir a atenção do "PRECIOSO". Quanto mais desprezível e vergonhoso, quanto mais mula maltratada e finita, talvez mais próximo da misericórdia divina e mais longe do esquecimento. Por isso a exposição do percurso feito até ali: do asno de Apuleius, ao

\footnotetext{
${ }^{26}$ HILST, H. Estar Sendo. Ter Sido. São Paulo: Globo, 2006 p. 123

${ }^{27}$ Idem, p. 124

${ }^{28}$ É uma referência à clássica história de Lucio Apuleio: As metamorfoses, ou $O$ asno de ouro, em que são relatadas as aventuras do jovem Lúcio, que é transformado por magia em asno e só recupera a forma humana graças à intervenção de Ísis, a cujo serviço se consagra.

${ }^{29}$ KARDEC A. Livro dos espíritos. in: http://www.scribd.com/doc/18068176/O-Livro-Dos-Espiritos Acesso em: 23 Jul. 2009. p. 558. "É a conseqüência de sua depuração, porquanto, à medida que se vão depurando, os Espíritos passam a encarnar em mundos cada vez mais perfeitos, até que se tenham despojado totalmente da matéria e lavado de todas as impurezas, para eternamente gozarem da felicidade dos Espíritos puros, no seio de Deus.”
} 
asno que transportou Jesus para entrar em Jerusalém, para o período em que foi um "ninguém" até o momento em que a voz do poeta-mula se pronuncia dizendo que seu estar sendo é apenas como "escombros de um alguém". "Caminhada", "estio", desculpas constantes pelo corpo atual, o "corpo nojoso [...] pulsante de outras vidas / mas tão triste e batido, tão crespo / de espessuras e de feridas ${ }^{30 "}$ " que leva o poeta-mula a um processo de dessubjetivação causado pela vergonha. Conforme Agamben,

na vergonha o sujeito não tem outro conteúdo senão a própria dessubjetivação, convertendo-se em testemunho do próprio desconcerto, da própria perda de si como sujeito. Esse duplo movimento, de subjetivação e de dessubjetivação, é a vergonha ${ }^{31}$.

O poeta-mula passa por esse processo, ao envergonhar-se, negar-se, compadecer-se de si mesmo cada vez mais, tenta fazer disso também um instrumento que chamará a atenção do "MAIS FORMOSO". Só que a vergonha, não é apenas consequência de um desapego cristão ou de uma dilapidação contínua do corpo como maneira de ascender, transcender, mas também de orgulho, de soberania do eu. Com esse discurso suplicante, inferiorizado por sua condição, entregue ao que não se pode assumir mas que é da sua própria intimidade, o poeta-mula tenta chegar ao sagrado manipulando uma provável bondade divina, inclusive demonstrando que sua condição de mula não é assim tão indigna, é até "festiva" e "doce" quando está banhada pelo amor divino. Seu estar sendo pode ser vergonhoso, mas revela-se também aquilo que Agamben chamou de "condomitância" entre ser sujeito e não ser sujeito, entre "perderse e possuir" e, sobretudo entre a "soberania" e a "servidão" 32 . A mula de Deus tem por primeira condição a pura servidão, o estar apta e preparada para o trabalho, pronta para os fardos e os chicotes, é feita apenas com "demasiada coitadez", esse rebaixamento demonstra que só existindo como a invisibilidade de um animal espúrio, o poeta, o poeta-mula pode, soberanamente, desejar mais que a possessão de Deus, ou que Ele leia suas "escrituras de pena", de "infinita tristura", o poeta-mula pode pedir o impossível: uma morte úmida e fresca, atenuadora do seu padecer e que o acolha na sua subjetividade, aquela que ele veio descascando ao longo do tempo:

Que eu morra junto ao rio.

O caudaloso frescor das águas claras

sobre o pelo e as chagas.

\footnotetext{
${ }^{30}$ HILST, H. Estar Sendo. Ter Sido. São Paulo: Globo, 2006 p. 125

${ }^{31}$ AGAMBEN, G. O que resta de Auschwitz. São Paulo: Boitempo, 2008.p. 110

${ }^{32}$ Idem p. 112
} 


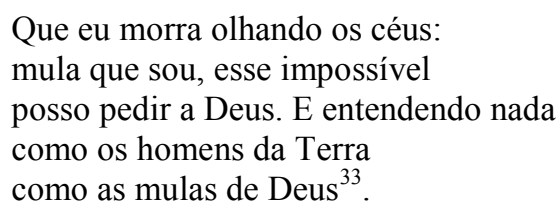

Bataille afirma que estar na frente do impossível quando mais nada é possível, "trata-se de fazer uma experiência do divino, é o análogo de um suplício ${ }^{34}$." O poetamula suplicia-se nesse desejo impossível, pois sua condição não lhe roga o direito à paz ou à salvação ou a contemplação dos céus. Tudo se configura numa "suplica infinita da ignorância", o poeta-mula sabe que o "homem não é contemplação", mas "súplica, guerra, angústia, loucura ${ }^{35}$ ", é como se houvesse uma tomada de consciência da sua nulidade e de sua fatuidade: ele não poderá morrer junto às águas claras, não terá as benesses de ser possuído por Deus, que de indiferente parece ter se tornado inexistente, mas, ao mesmo tempo, não tem mais escolha de ir adiante, chegou "ao extremo do possível” o "ponto onde, apesar da posição ininteligível que ele tem no ser, um homem, tendo-se despojado de logro e de temor, avança tão longe que não possamos conceber uma possibilidade de ir mais adiante ${ }^{36,}$, sem poder ir adiante, mas também impossibilitado de voltar, de romper o círculo vicioso da espera da possessão, cabe ao poeta-mula ser apenas "o indizível casqueando o nada", resta aceitar sua condição final, postar-se diante do impossível pedido a Deus e silenciar, feito uma boa mula, feito um bom poeta.

\section{REFERÊNCIAS}

AGAMBEN. Giorgio. Ideia da prosa. Lisboa: Cotovia, 1999.

. Profanações. São Paulo: Boitempo, 2007.

O fim do poema. in: Cacto. 2002

O que resta de Auschwitz. São Paulo: Boitempo, 2008.

ANTELO, Raúl. O autor como gesto. À memória de Ronaldo Assunção: In Alea: Estudos Neolatinos. Print version ISSN 1517-106X. Alea vol.7 no.2 Rio de Janeiro

\footnotetext{
${ }^{33}$ Hilst, H. Estar Sendo. Ter Sido. São Paulo: Globo, 2006 p. 127

${ }^{34}$ BATAILlE, G. A experiência interior. Série Temas, vol. 18. São Paulo: Ática, 1992 p. 39

${ }^{35}$ Idem, p. 42

${ }^{36}$ Idem, p. 45
} 
Jul/Dec. 2005. Disponível em: http://www.scielo.br/scielo.php?pid=S1517106X2005000200011\&script=sci_arttext. Acesso em: 26 Jul. 2009

BATAILlE, Georges. A experiência interior. Série Temas, vol 18. São Paulo: Ática, 1992.

Adriana Hildalgo, 2008.

La conjuracíon sagrada. Ensayos 1929-1939. Buenos Aires:

BLANCHOT, Maurice. A conversa Infinita - a experiência limite. São Paulo: Escuta, 2007.

DERRIDA, J. Che cos'é la poesia? In: Inimigo Rumor. n. 10. Rio de Janeiro: 7 Letras, maio 2001.

DUARTE, Edson Costa. Hilda Hilst - A Poética da Agonia e do gozo. In: Revista Agulha. Disponível em: http://www.revista.agulha.nom.br/hilda.html. Acesso em: 24 Jul. 2009.

HILST, Hilda. Estar sendo. Ter sido. São Paulo: Globo, 2006

Poemas malditos, gozosos e devotos. São Paulo: Globo, 2005.

KARDEC A. Livro dos espíritos. Disponível em: http://www.scribd.com/doc/18068176/O-Livro-Dos-Espiritos. Acesso em: 23 Jul. 2009.

PECÓRA, Alcir. Hilda Hilst: call for papers. Germina Literatura. Disponível em: http://www.germinaliteratura.com.br/literatura ago2005 pecora.htm. Acesso em: 24 Jul. 2009.

Globo, 2006.

. Nota do organizador. In: Estar Sendo. Ter Sido. São Paulo: São Paulo: Globo, 2005.

Nota do Organizador. In: Poemas malditos, gozosos e devotos.

PERNIOLA, Mario. Enigmas. Egipcio, barroco y neo-barroco em la sociedad y El arte. Murcia: CendeaC / Ad litteram Ensayo, 2005. 